\title{
UMA AVALIAÇÃO PRELIMINAR DA INFLUÊNCIA DO CLIMA E DOS FRATURAMENTOS NOS TEORES DE FERRO DA ÁGUA SUBTERRÂNEA NO DOMÍNIO DAS ROCHAS CRISTALINAS DO ESTADO DA BAHIA
}

CARMO, J. C. C.

Companhia de Engenharia Ambiental e Recursos Hídricos da Bahia - CERB

Universidade Federal da Bahia, Salvador, Bahia, Brasil, jcccarmo@ hotmail.com

\section{OLIVEIRA, I. B.}

Universidade Federal da Bahia, Salvador, Bahia, Brasil, oliveira@ufba.br

Resumo: Este artigo apresenta de forma sucinta a influência do clima e dos fraturamentos nos teores de ferro total na água subterrânea do Estado da Bahia, no domínio das rochas cristalinas. Para alcançar o objetivo foram selecionados 1.688 poços tubulares profundos construídos pela CERB, no período 2003-2013, e suas análises da água subterrânea, submetidas a tratamentos estatísticos. Os resultados obtidos mostraram que 468 amostras, ou 27,70\% do universo pesquisado, apresentaram teores elevados de ferro. As concentrações elevadas de ferro foram espacializadas, resultando em mapas das áreas críticas para a explotação da água subterrânea destinada ao abastecimento público. O mapeamento das áreas com ferro alto $(>0,3 \mathrm{mg} / \mathrm{L})$ e o conhecimento, embora preliminar, da influência desses fatores nas concentrações de ferro nas águas subterrâneas assumem relevância nos estudos hidrogeológicos e na prospecção da água subterrânea, na tentativa de evitar os sítios com elevados teores de ferro e água imprópria para o consumo humano.

\begin{abstract}
This article briefly presents the influence of climate and fracturing on the total iron content of the state of Bahia groundwater in the crystalline rocks hydrogeological domain. To achieve the goal this work selected 1,688 deep wells with flux $\geq 1.0 \mathrm{~m}^{3} / \mathrm{h}$, perforated by CERB in the period 2003-2013, and developed statistical treatment of the groundwater chemical analysis. The results showed that, 468 samples, or $27.70 \%$ of the studied deep wells, showed high levels of iron (>0.3 mg / L). Maps of the distribution of high iron concentrations showed the critical areas for exploitation of groundwater for public supply. The knowledge of both, the areas with high iron concentrations, and the influence of the factors, climate and fracturing on iron concentrations in groundwater, although preliminary, assume relevance for both, hydrogeological studies and ground water prospection in an attempt to avoid sites with high iron content and water unfit for human consumption.
\end{abstract}

Palavras-chaves: água subterrânea; ferro; domínio cristalino.

Keywords: groundwater; iron; crystalline domain. 


\section{1 - INTRODUÇÃO}

Os teores elevados de ferro na água subterrânea encontram-se associados a todos os domínios hidrogeológicos do Estado da Bahia (CARMO, 2016).

Com base no Banco de Dados da Companhia de Engenharia Ambiental e Recursos Hídricos da Bahia - CERB, dos poços perfurados no domínio das rochas cristalinas $27,70 \%$ apresentaram teores elevados de ferro total na água. Assim, vários poços deixaram de ser instalados para o abastecimento público, trazendo prejuízos financeiros para o Estado e para as comunidades, a frustração ao ver o poço perfurado com água doce e, em seguida, a impossibilidade de aproveitamento da água para o consumo humano, devido ao custo do tratamento da água.

O domínio das rochas cristalinas compreende aproximadamente $40 \%$ do território baiano, conforme demonstrado no mapa da Figura 1.
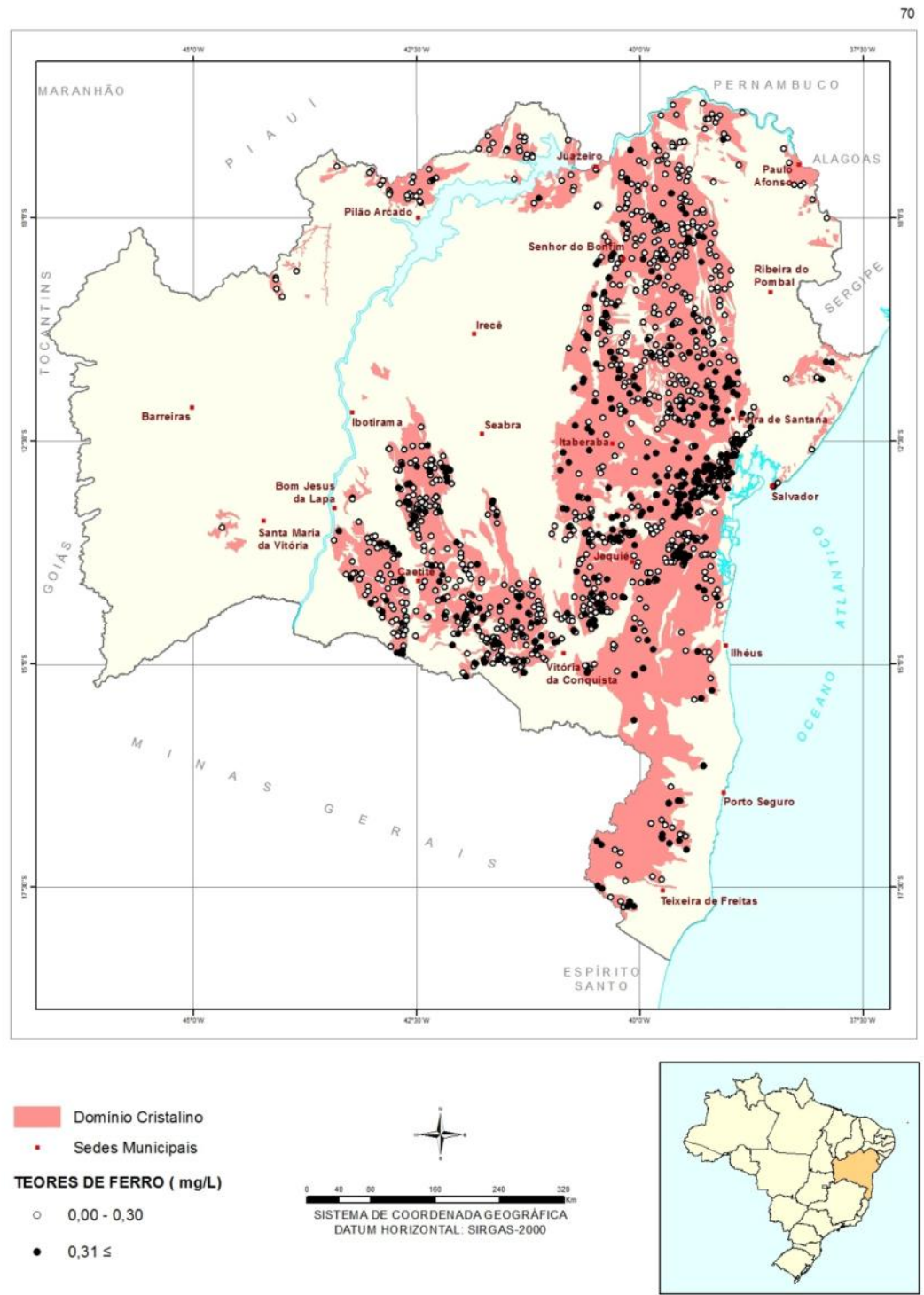

Figura 1. Mapa de localização dos 1.688 poços com teores de ferro abaixo e acima de $0,3 \mathrm{mg} / \mathrm{L} \mathrm{e}$ vazão $\geq 1,0 \mathrm{~m}^{3} / \mathrm{h}$, no domínio hidrogeológico das rochas cristalinas. Fonte: CARMO, 2016. 
Devido à grave problemática da presença de excesso de ferro na água subterrânea do Estado da Bahia, buscou-se sistematizar nesse trabalho informações sobre a influência dos fatores climáticos e dos fraturamentos na concentração de ferro na água subterrânea, no domínio das rochas cristalinas.

O objetivo é auxiliar os especialistas nos estudos hidrogeológicos para melhorar o aproveitamento dos poços perfurados nas áreas potencialmente comprometidas com ferro, pela a inserção de critérios alternativos de locação de poços.

\section{2 - METODOLOGIA}

Para o levantamento dos poços tubulares profundos foi utilizado o Banco de Dados Hidrogeológicos da CERB, com cerca de vinte e três mil e quatrocentos poços tubulares cadastrados, dos quais, quinze mil e setecentos poços foram construídos diretamente pela CERB e por empresas contratadas, mas, sob a sua fiscalização.

Foram selecionados todos os poços que apresentaram vazão de teste de bombeamento $\geq 1 \mathrm{~m}^{3} / \mathrm{h}$ e laudo da análise físico-química da água completo, tomando-se como referência o período de 2003 a 2013. Assim, foram selecionados dois grupos: a) poços contendo água com concentração de ferro $\leq 0,3 \mathrm{mg} / \mathrm{L} \mathrm{e} \mathrm{b)} \mathrm{aqueles} \mathrm{com} \mathrm{valores} \mathrm{de} \mathrm{ferro}$ acima desse parâmetro. Embora o primeiro grupo de poços apresente água subterrânea de qualidade para o consumo humano quanto ao teor de ferro, eles foram utilizados na confecção dos mapas de localização dos poços perfurados para melhor visualização e correlação da distribuição dos teores de ferro nas águas subterrâneas do Estado da Bahia.

Devido à enorme extensão de área que compõe este domínio, ele foi subdividido em três compartimentos: Cristalino Centro-Norte, Cristalino Centro-Sul e Cristalino Sudoeste.

A análise de cada compartimento foi feita a partir da individualização de faixas que foram identificadas com base na disposição espacial de densidade dos poços tubulares (aglomerados e dispersos) que apresentaram ferro em excesso em suas águas. Para delimitar essas faixas, tomou-se como referência o fator climático e a partir daí buscouse estabelecer relação com a geologia. 


\section{3 - RESULTADOS OBTIDOS E ANÁLISES}

\section{1 - Distribuição dos teores de ferro da água subterrânea do Estado da Bahia}

O mapa da Figura 2 apresenta a localização dos poços com teores de ferro abaixo e acima de $0,3 \mathrm{mg} / \mathrm{L}$ e vazão $\geq 1 \mathrm{~m}^{3} / \mathrm{h}$, distribuídos por tipos de climas, no compartimento Cristalino Centro-Norte.
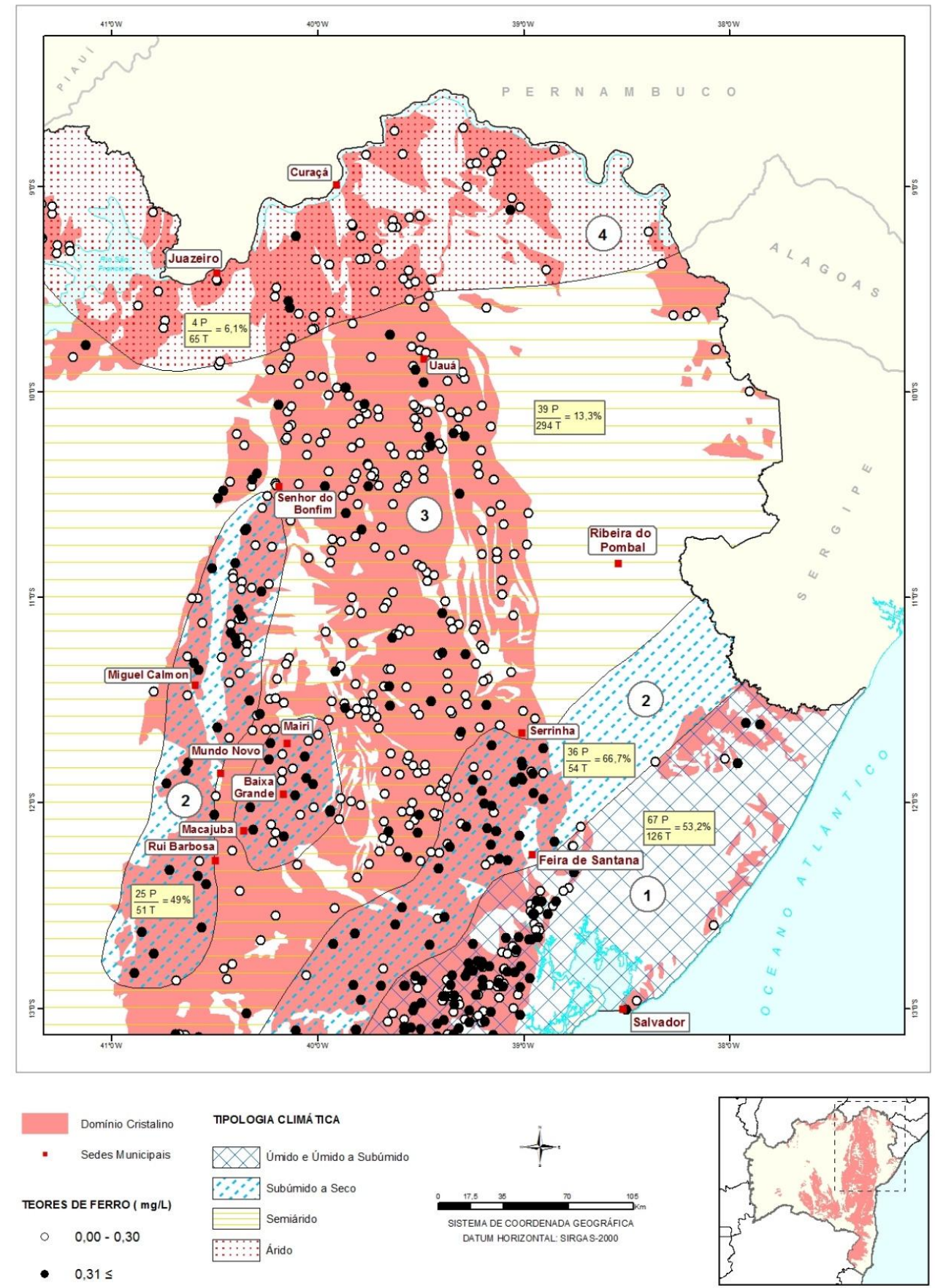

Figura 22. Mapa de localizaçăo dos poços com teores de ferro abaixo e acima de $0,3 \mathrm{mg} / \mathrm{L}$, por tipo de clima, no compartimento Cristalino Centro-Norte. Fonte: 0

Figura 2. Mapa de localização dos poços com teores de ferro abaixo e acima de $0,3 \mathrm{mg} / \mathrm{L}$ e vazão $\geq 1,0$ $\mathrm{m}^{3} / \mathrm{h}$, por tipo de clima, no compartimento Cristalino Centro-Norte. Fonte: CARMO, 2016. 
O mapa mostra a existência de quatro tipos de clima nesse compartimento, distribuídos de Sul para Norte da seguinte forma: úmido e úmido a subúmido; subúmido a seco; semiárido; e, árido. Assim sendo, o compartimento foi subdividido em quatro faixas para análise.

A faixa 1 corresponde a área situada na parte mais a sul do compartimento. Ela está submetida aos climas úmido e úmido a subúmido e tem como cobertura vegetal a mata atlântica. Observa-se nessa faixa um forte contingente de poços tubulares perfurados contendo teores elevados de ferro na água $(53,2 \%)$.

A faixa 2 é uma área contígua à primeira e tem como principais características o clima subúmido a seco e vegetação de florestas secas do Nordeste. Fazem parte também dessa faixa, duas outras áreas: uma no centro e outra a leste do compartimento, as quais compartilham as mesmas características climáticas. A área mais a centro estende-se do município de Várzea do Poço ao município de Macajuba e a área mais a leste vai desde o município de Antônio Gonçalves até o município de Boa Vista do Tupim. Na área contígua à faixa 1 constata-se uma forte densidade de poços perfurados com ferro alto $(66,7 \%)$ e nas áreas central e mais a leste do compartimento a tendência de alta aglomeração de poços com ferro alto se mantém (49\%).

A faixa 3 corresponde a maior área do compartimento Cristalino Centro-Norte. Caracteriza-se por apresentar clima semiárido e vegetação de caatinga. Embora tenha sido perfurado nesta área uma grande quantidade de poços tubulares no período estudado (294 poços), poucos deles apresentaram água com altos teores de ferro $(13,3 \%)$.

A faixa 4 localiza-se na parte do extremo norte do compartimento, sob o clima árido, o mais severo do Estado. A vegetação característica desta faixa é a caatinga. Foram perfurados 65 poços tubulares nessa área, e apenas 4 poços apresentaram altos teores de ferro na água $(6,1 \%)$.

Dessa forma foi possível estabelecer uma relação entre a densidade de poços com altos teores de ferro na água subterrânea da Bahia e os tipos de clima (Tabela 1).

Tabela 1. Relação entre as condições climáticas e a distribuição de poços com $\mathrm{Fe}>0,3$ $\mathrm{mg} / \mathrm{L}$ no compartimento Cristalino Centro-Norte

\begin{tabular}{llll}
\hline Faixa & Clima & Densidade de poços & Percentual \\
\hline 1 & Úmido e úmido a subúmido & Forte & 53,2 \\
2 & Subúmido a seco & Forte & 66,7 e 49 \\
3 & Semiárido & Fraca & 13,3 \\
4 & Árido & Muito fraca & 6,1 \\
\hline
\end{tabular}

Fonte: CARMO, 2016. 
O Quadro 1 apresenta a geologia predominante do compartimento Cristalino CentroNorte, por faixas climáticas.

Quadro 1. Distribuição das unidades litológicas por faixas climáticas, no compartimento Cristalino Centro-Norte

\begin{tabular}{|c|c|c|}
\hline Faixa & Clima & Unidade litológica predominante \\
\hline 1 & Úmido e úmido a subúmido & Granulitos. \\
\hline 2 & Subúmido a seco & $\begin{array}{lrr}\text { Granulitos, } & \text { gnaisses, } & \text { migmatitos, } \\
\text { anfibolitos, } & \text { corpos } & \text { máfico- } \\
\text { ultramáficos } & \text { greenstone belts e suíte } \\
\text { máficar } & \end{array}$ \\
\hline 3 & Semiárido & $\begin{array}{lrr}\text { Granulitos, } & \text { gnaisses, } & \text { migmatitos, } \\
\text { anfibolitos, } & \text { corpos } & \text { máfico- } \\
\text { ultramáficos greenstone belts e diques } & \\
\text { máficos. } & \end{array}$ \\
\hline 4 & Árido & $\begin{array}{l}\text { Gnaisses, migmatíticos, anfibolitos, } \\
\text { corpos máfico-ultramáficos } \\
\text { greenstone belt. }\end{array}$ \\
\hline
\end{tabular}

Fonte: CARMO, 2016.

Os dados do Quadro 1 indicam que em escala regional o compartimento Cristalino Centro-Norte não apresenta grandes variações litológicas, podendo a rocha neste caso ser considerada como uma unidade de igual importância nas quatro faixas climáticas. $\mathrm{O}$ clima, por sua vez, apresenta grandes variações no espaço (variando de úmido a árido), levando a estabelecer uma relação de influência com os teores de ferro encontrados nas águas subterrâneas. Percebe-se no mapa da Figura 2 uma diminuição no número de poços com alto teor de ferro no sentido de menor pluviometria (clima árido). 
O mapa da Figura 3 exibe a localização dos poços com teores de ferro abaixo e acima de $0,3 \mathrm{mg} / \mathrm{L}$ e vazão $\geq 1 \mathrm{~m}^{3} / \mathrm{h}$, distribuídos por tipo de clima, no compartimento Cristalino Centro-Sul.
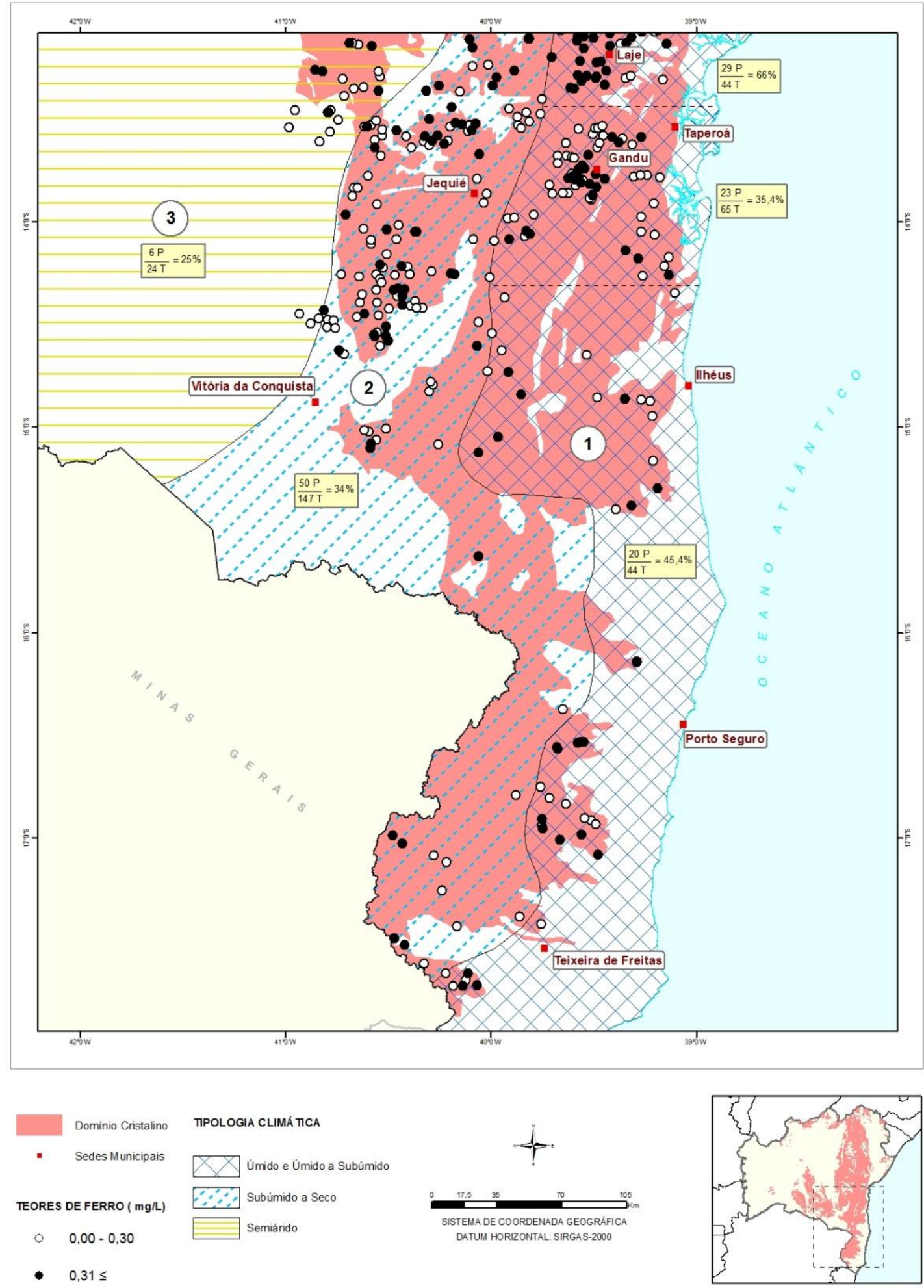

Figura 23. Mapa de localização dos poços com teores de ferro abaixo e acima de $0,3 \mathrm{mg} / \mathrm{L}$, por tipo de clima, no comprtimento Cristalino Centro-Sul. Fonte: 0 Autor.

Figura 3. Mapa de localização dos poços com teores de ferro abaixo e acima de $0,3 \mathrm{mg} / \mathrm{L}$ e vazão $\geq 1,0$ $\mathrm{m}^{3} / \mathrm{h}$, por tipo de clima, no compartimento Cristalino Centro-Sul. Fonte: CARMO, 2016. 
Nesse compartimento ocorrem três tipos de climas: úmido e úmido a subúmido; subúmido a seco; e, semiárido.

A faixa 1 (leste) é um prolongamento da faixa 1 do compartimento Cristalino CentroNorte. À vista disto, apresenta características análogas: clima úmido e úmido a subúmido, vegetação de mata atlântica e granutilos predominantemente como rocha matriz.

Duas áreas de maior concentração de poços com ferro em excesso se destacam nessa faixa: a primeira com $66 \%$ de poços com ferro alto compreende os municípios de Aratuípe, Lajes, Mutuípe e Jequiriçá e a segunda com 35,4\% abrange os municípios de Taperoá, Teolândia, Gandu, Piraí do Norte, Itamarí e Nova Ibiá.

$\mathrm{Na}$ área que se estende da parte mediana até o extremo sul do compartimento, de mesmas condições de clima e de rocha, os poços com altas concentrações de ferro apresentam-se mais dispersos; o que pode ser ocasionado pela menor quantidade de perfurações pela CERB. Entretanto, $45,4 \%$ destes poços possuem ferro alto. Esta região apresenta excesso hídrico, fruto dos grandes volumes de chuvas que ocorrem anualmente, o que reforça a importância do clima na evolução dos teores de ferro nas águas subterrâneas do Estado da Bahia.

A faixa 2, situada no centro, é também uma continuidade da faixa 2 do compartimento anterior. Apresenta clima subúmido a seco, vegetação de florestas do interior da Bahia, granulitos como rochas predominantes e um número significativo de poços perfurados contendo elevados teores de ferro (34\%).

A faixa 3 é uma estreita área localizada no lado oeste do compartimento, de clima semiárido, vegetação de caatinga e granulitos no substrato. 6 poços foram identificados nesta faixa contendo ferro em excesso de um total de 24 poços perfurados, ou $25 \%$. 
O mapa da Figura 4 corresponde à localização dos poços com teores de ferro abaixo e acima de $0,3 \mathrm{mg} / \mathrm{L}$ e vazão $\geq 1 \mathrm{~m}^{3} / \mathrm{h}$, distribuídos por tipo de clima, no compartimento Cristalino Sudoeste.
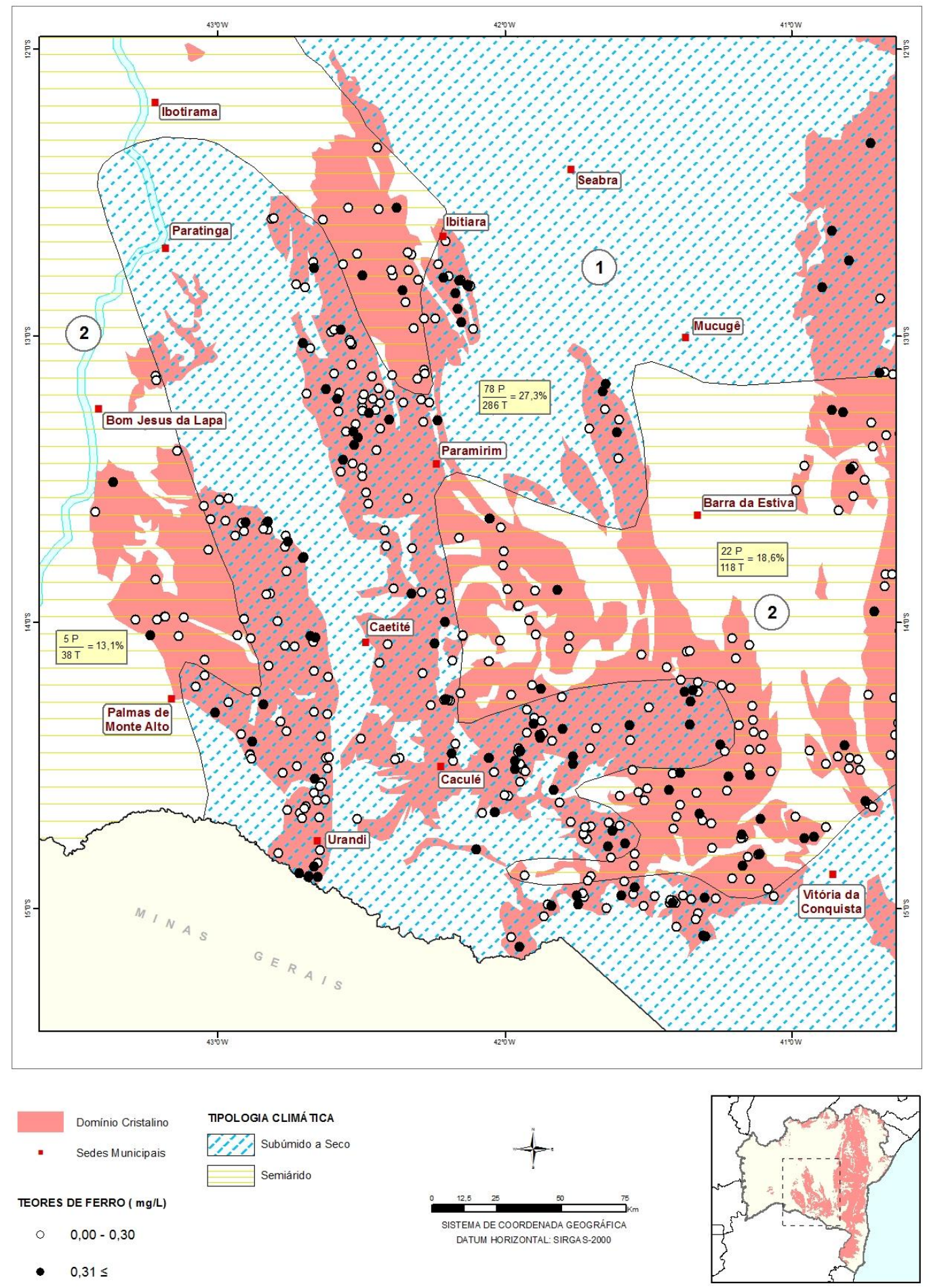

Figura 24. Mapa de localização dos poços com teores de ferro abaixo e acima de $0,3 \mathrm{mg} / \mathrm{L}$, por tipo de clima, no comprtimento Cristalino Sudoeste. Fonte: 0 Autor

Figura 4. Mapa de localização dos poços com teores de ferro abaixo e acima de $0,3 \mathrm{mg} / \mathrm{L}$ e vazão $\geq 1,0$ $\mathrm{m}^{3} / \mathrm{h}$, por tipo de clima, no compartimento Cristalino Sudoeste. Fonte: CARMO, 2016. 
Nesse compartimento ocorrem dois tipos de climas: subúmido a seco e semiárido, sendo, portanto, o compartimento subdividido em duas faixas. O mapa mostra que onde ocorre o clima subúmido a seco (faixa 1-centro do compartimento), existem 78 poços contendo ferro em excesso, para um total de 286 poços, ou $27,3 \%$.

Nas faixas de clima semiárido os percentuais de poços com ferro alto reduz para 18,6 e $13,1 \%$. Os poços ricos em ferro nesse compartimento estão localizados nas unidades litológicas de caráter básico, ou próximos delas, conforme demonstrado na Tabela 2.

Tabela 2. Municípios com maiores densidades de poços com $\mathrm{Fe}>0,3 \mathrm{mg} / \mathrm{L}$ por unidade litológica no compartimento Cristalino Sudoeste

\begin{tabular}{ll}
\hline Municípios & Unidades Litológicas \\
\hline Novo Horizonte & Sequência metavulcânica Ibiajara \\
Macaúbas-Botuporã & Greenstone belt Boquira \\
Riacho de Santana-Igaporã & Greenstone belt Riacho de Santana \\
Caetíté-Guanambi-Candiba-Pindaí-Urandi & Complexo Santa Isabel \\
$\begin{array}{lll}\text { Lagoa Real-Ibiassuçê-Caculé } \\
\text { Brumado-Malhada de Pedras-Guajeru- } \\
\text { Presidente Jânio Quadros }\end{array}$ & $\begin{array}{l}\text { Greenstone belt Ibitira-Ubiraçaba belt Brumado e } \\
\text { greenstone belt Guajeru }\end{array}$ \\
\hline
\end{tabular}

Fonte: CARMO, 2016.

Conforme exposto, em todos os compartimentos do domínio hidrogeológico das rochas cristalinas, as maiores densidades de poços contendo alto teor de ferro ocorrem nas faixas de climas úmido e úmido a subúmido e subúmido a seco. Essa tendência se modifica à medida que vai diminuindo o volume de chuvas na região: fraca densidade em clima semiárido e muito fraca, em região de clima árido.

Por outro lado, fica também evidenciado que a existência de unidades litológicas potencialmente ricas em ferro em regiões de climas semiárido e árido não compromete a qualidade química da água subterrânea, no quesito ferro. Isto se deve, provavelmente, à fraca atuação do intemperismo químico sobre a rocha matriz para formar o manto de decomposição (regolito), devido ao baixo volume de chuvas, e, consequentemente a existência de escassez hídrica nessas regiões. 


\section{2 - Distribuição das entradas de águas (E.A) por faixa de profundidade}

A Tabela 3 refere-se à distribuição das entradas de água (E.A), em percentual, por faixa de profundidade, no domínio das rochas cristalinas.

Tabela 3. Percentual de ocorrência das entradas de água por faixa de profundidade

\begin{tabular}{cc}
\hline Faixa de profundidade de E.A (m) & Percentual de ocorrência (\%) \\
\hline $0-25$ & 30,49 \\
$25-50$ & 39,30 \\
$50-75$ & 20,04 \\
$>75$ & 10,17
\end{tabular}

Fonte: CARMO, 2016.

A Tabela mostra que quase $70 \%$ das entradas de água que compõem o aquífero fraturado do domínio das rochas cristalinas se concentram até a profundidade de 50 metros, sendo que $30,49 \%$ delas ocorrem entre o manto decomposto e a profundidade de 25 metros.

A ocorrência de fraturamentos próximos à superfície do terreno pode contribuir para a hidroquímica da água subterrânea. Através desses fraturamentos circulam as águas pluviométricas que adentram o solo, percolam o manto decomposto e levam para o aquífero os elementos químicos residualmente enriquecidos no regolito.

Para exemplificar a importância dos fraturamentos nos teores de ferro nesse domínio hidrogeológico, foram selecionados 136 poços com os mais altos teores de ferro encontrados na água: 2,00 a 33,30 mg/L. Os resultados mostram que destes apenas 15 poços, ou seja; $11 \%$ tiveram entradas de água na profundidade superior a 50 metros, significando que $89 \%$ dos poços restantes apresentam fraturamentos mais superficiais $(0$ a $50 \mathrm{~m})$.

Todavia, convém ressaltar que a água coletada de poço tubular é resultante do somatório das águas que percolam por todos os fraturamentos identificados durante os serviços de perfuração. Não sendo possível, portanto, dado ao caráter regional desta pesquisa, estabelecer tecnicamente uma relação de evolução dos teores de ferro da água subterrânea com as profundidades de entradas de água do poço. 


\section{4 - CONCLUSÃO}

Os resultados da pesquisa mostraram que no domínio das rochas cristalinas, em regiões de climas úmido, úmido a subúmido e subúmido a seco ocorre um forte contingente de poços tubulares perfurados contendo teores elevados de ferro na água $(53,2 \%)$.

A existência de unidades litológicas potencialmente ricas em ferro em regiões de climas de baixa pluviometria não compromete a qualidade química da água subterrânea, no quesito ferro, por não apresentar preponderantemente poços com alto teor de ferro. Foi constatada uma significativa diminuição no número de poços com alto teor de ferro no sentido de menor pluviometria (13,3\% para o clima semiárido e $6,1 \%$ para o clima árido).

A pesquisa também conclui que a evolução dos teores de ferro na água subterrânea depende fundamentalmente da combinação de fatores naturais, com destaque para clima versus litologia.

De modo geral, no sistema aquífero cristalino, os fraturamentos transversais mais próximos da superfície do terreno tendem a ser mais abertos e mais intercomunicáveis do que os sistemas de fraturas de maior profundidade, vindo a permitir que ocorram maiores fluxos de água subterrânea nesta faixa de profundidade (daí a maior capacidade específica dos poços em menor profundidade). Logo, as entradas de águas, que correspondem às profundidades de fraturamentos, podem contribuir para a elevação dos teores de ferro nas águas subterrâneas.

Este trabalho pode contribuir no desenvolvimento de projetos que visem melhor aproveitar os poços tubulares já perfurados, bem como intensificar os estudos hidrogeológicos visando a diminuir a perfuração de poços tubulares com teores de ferro fora do padrão de potabilidade, e assim, melhorar o atendimento com água de qualidade às comunidades.

\section{AGRADECIMENTO}

Os autores agradecem à CERB pela cessão dos dados de hidroquímica da água subterrânea constante em seu Banco de Dados Hidrogeológicos; e pelo uso de seu software corporativo COORPORE.

\section{REFERÊNCIAS}

CARMO, J. C. C. Ferro na água subterrânea do Estado da Bahia: uma avaliação preliminar dos fatores influentes na concentração. Dissertação de Mestrado, UFBA, Escola Politécnica da Universidade Federal da Bahia. Salvador, 2016. 123 p. 
COMPANHIA DE ENGENHARIA AMBIENTAL E RECURSOS HÍDRICOS DA BAHIA. Dados hidrogeológicos de poços. Salvador: Divisão de Cadastro Hidrogeológico, 2014.

OLIVEIRA, I. B.; NEGRÃO, F. I.; SIVA, A. G. L. S. Mapeamento dos aquíferos do Estado da Bahia utilizando o índice de qualidade natural das águas subterrâneas IQNEAS. Águas Subterrâneas, v. 21, n. 1, p.123-137, 2007. 